\title{
Seroprevalencia de anticuerpos contra el virus de la diarrea viral bovina en bovinos de crianza extensiva en tres distritos de Ayacucho, Perú
}

\author{
Seroprevalence of antibodies against bovine viral diarrhoea virus in cattle under \\ an extensive production system in three districts of Ayacucho, Peru \\ Catherine Arbulú-García ${ }^{1}$; Siever Morales-Cauti ${ }^{1,2,3}$
}

\section{Resumen}

El presente estudio tuvo por objetivo determinar la seroprevalencia de anticuerpos contra el virus de la diarrea viral bovina (VDVB) en los distritos de Chumpi, Coracora y Pullo, región de Ayacucho, en marzo de 2018. Se recolectaron 460 muestras de sangre de bovinos de ambos sexos y mayores de cuatro meses de comunidades campesinas con manejo extensivo. Las muestras de suero fueron analizadas mediante un kit comercial de ELISA indirecta. El 82.56 $\pm 3.44 \%(367 / 460)$ de los animales presentaron anticuerpos contra el VDVB, presentándose en Pullo la mayor prevalencia corregida (89.74 $\pm 2.75 \%$; $83 / 96)$. La alta prevalencia corregida que se reporta evidencia una amplia distribución de la enfermedad.

Palabras clave: diarrea viral bovina, anticuerpos, bovino, crianza extensiva

${ }^{1}$ Carrera de Medicina Veterinaria y Zootecnia, Universidad Cientifica del Sur, Lima, Perú

${ }^{2}$ Laboratorio de Microbiología y Parasitología Veterinaria, Facultad de Medicina Veterinaria, Universidad Nacional Mayor de San Marcos, Lima, Perú

${ }^{3}$ Email: sieverm@hotmail.com; https://orcid.org/0000-0002-5396-8889

Recibido: 2 de octubre de 2020

Aceptado para publicación: 19 de marzo de 2021

Publicado: 23 de junio de 2021

CLos autores. Este artículo es publicado por la Rev Inv Vet Perú de la Facultad de Medicina Veterinaria, Universidad Nacional Mayor de San Marcos. Este es un artículo de acceso abierto, distribuido bajo los términos de la licencia Creative Commons Atribución 4.0 Internacional (CC BY 4.0) [https:// creativecommons.org/licenses/by/4.0/deed.es] que permite el uso, distribución y reproducción en cualquier medio, siempre que la obra original sea debidamente citada de su fuente original 
The present study aimed to determine the seroprevalence of antibodies against bovine viral diarrhoea virus (BVDV) in the districts of Chumpi, Coracora and Pullo, Ayacucho region, in March 2018. In total, 460 blood samples were collected from cattle from both sexes and older than four months of age, from rural communities under extensive breeding system. The serum samples were analysed using a commercial indirect ELISA kit. The results showed that $82.56 \pm 3.44 \%$ (367/460) of the animals presented antibodies against BVDV, with the greatest corrected prevalence in Pullo $(89.74 \pm 2.75 \%$; 83/96). The high corrected prevalence reported shows a wide distribution of the disease.

Key word: bovine viral diarrhoea, antibodies, bovine, extensive breeding

\section{INTRODUCCIÓN}

El sector ganadero en Perú, según el censo agropecuario del 2012 del Instituto Nacional de Estadística e Informática (INEI) es de 5156044 de cabezas de ganado (INEI, 2012), correspondiendo el $78 \%$ de la población bovina a la sierra, mayormente en manos de comunidades campesinas y en explotaciones extensivas privadas (Rosemberg, 2018). La población bovina en la región Ayacucho es de 414066 bovinos, y en la provincia de Parinacochas es de 49 275. En esta provincia, los pobladores tienen como principal actividad económica a la ganadería (Aronés et al., 2003; INEI, 2012).

Debido a la importancia económica que genera el ganado bovino es fundamental mantener un buen estado de salud de los animales, lo cual dependerá principalmente de las condiciones medioambientales y de crianza, así como de la presencia de patógenos. Por tal motivo, el Organismo Mundial de Sanidad Animal (OIE) (OIE, 2021) y el Servicio Nacional de Sanidad Agraria (SENASA) establecen una lista de enfermedades notificables en el territorio nacional, dentro de las cuales se hace mención a la diarrea viral bovina (DVB) (SENASA, 2015). En el país se reportado prevalencias no menores de $35 \%$ en
Lima y hasta de $96 \%$ en los valles de Huancayo; y de $85 \%$ en la provincia de Parinacochas (Rivera et al., 2001; Ståhl et al., 2002; Aguilar et al., 2006).

La DVB es una enfermedad infectocontagiosa con amplia distribución mundial. El agente causal presenta un genoma en base de ácido ribonucleico (ARN), y pertenece al género Pestivirus de la familia Flaviviridae (Arauco y Lozano, 2018; Ricci et al., 2019).

Se conocen dos biotipos del virus, el biotipo citopático $(\mathrm{CP})$ origina vacuolización citoplasmática y destrucción de la monocapa celular dentro de pocos días de la infección y surge por mutación de virus no citopático (NCP) y el biotipo no citopático (NCP) que no causa daños visibles, es a su vez el más importante del pestivirus, esto debido a que es el único que atraviesa la placenta, invade el feto configurándose la infección persistente y siendo esta la principal causa de propagación del virus (Nettleton y Entrican, 1995; Fulton et al., 2003; Bolin y Grooms, 2004; Araínga et al., 2010). En cuanto a genotipos, hay diferencias a nivel molecular que han permitido agrupar las cepas como VDVB-1 y VDVB-2. E1 VDVB-1 cuenta con 11 subgenotipos y es el más difundido entre las poblaciones bovinas, siendo sus cepas empleadas en la elaboración de vacunas; mien- 
tras que del VDVB-2 se conocen dos subgenotipos (Araínga et al., 2010; Yesilbalg et al., 2017; Neill et al., 2019); además el genotipo identificado en el país es el VDVB1 (Araínga et al., 2010).

La vía de infección más frecuente de la DVB son los animales persistentemente infectados (PI), los cuales eliminan el virus durante toda su vida por medio de fluidos corporales como la saliva, semen, orina, heces y leche. Los animales con infección aguda también corresponden a una fuente de infección, aunque menos relevante, ya que eliminan el virus en menos cantidad y solo por el tiempo que dure la infección (Lértora, 2003; Brodersen, 2014; Lanyon et al., 2014). La transmisión, por lo tanto, es de tipo vertical u horizontal (Vilcek et al., 2005).

Las infecciones agudas se dan con más frecuencia en animales jóvenes y dependen de la cepa que le infecte, siendo más común la NCP. El periodo de incubación es entre 5 y 7 días (Lanyon et al, 2014). El virus se replica en las células epiteliales de la mucosa oronasal y tonsilas, y se disemina por las vías sanguínea y linfática (Lértora, 2003; Brodersen, 2014). La infección por el VDVB origina inmunosupresión sistémica, potenciando infecciones secundarias ya sean de otros virus o bacterias como: Parainfluenza tipo 3, virus de la Rinotraqueitis Infecciosa Bovina (IBR), Mannheimia haemolytica, Pasteurella multocida, y Mycoplasma bovis, entre otras (Fulton et al., 2002; Lértora, 2003).

El diagnóstico del VDVB consta de signos y lesiones inespecíficas, por lo que es necesario emplear técnicas de laboratorio, ya sea para detectar al virus, anticuerpos o componentes virales. Para la detección de compuestos virales existen diversos métodos serológicos, inmunohistoquímicos y moleculares (Lanyon et al., 2014), siendo el ensayo por ELISA para la detección de anticuerpos uno de los métodos diagnósticos más utilizados por facilitar el análisis de un amplio número de muestras (Stahl et al., 2002; Sandvik, 2005).
El presente estudio tuvo por objetivo determinar la seroprevalencia de anticuerpos contra el VDVB en tres distritos de la región de Ayacucho en 2018.

\section{Materiales y MéTodos}

El presente trabajo se llevó a cabo en los distritos Chumpi, Coracora y Pullo de la provincia de Parinacochas, ubicada al sur de Ayacucho, Perú. Estos distritos se encuentran a altitudes entre 3000 y $3200 \mathrm{msnm}$ (Aronés et al., 2003). El procesamiento de las muestras se realizó en el Laboratorio de Microbiología de la Universidad Científica del Sur, en Lima. El muestreo de tipo aleatorio fue realizado durante los meses de febrero y marzo de 2018, participando animales mayores a cuatro meses de edad.

El cálculo del tamaño de muestra se realizó según la fórmula de tamaño de muestra para poblaciones finitas (Wayne, 2012). La población total evaluada fue de 27063 bovinos, siendo de 5339 en Chumpi, 13988 en Coracora y 7736 en Pullo, tomando como referencia el estudio de Rivera et al. (2001) en el área de estudio con una prevalencia de $85.3 \%$, un nivel de confianza de $95 \%$ y un error de $5 \%$, obteniéndose un tamaño mínimo de muestra de 193 animales. Al estratificar las muestras requeridas para cada distrito según su población referencial, se obtuvo 38 animales para Chumpi, 100 para Coracora y 55 para Pullo; sin embargo, se incrementó el muestreo debido a la disponibilidad de reactivos, materiales y factibilidad al momento del muestreo, desarrollándose el estudio con 460 muestras.

Las muestras de sangre fueron colectadas mediante punción en la vena yugular con agujas N. ${ }^{\circ} 18$ y tubos Vacutainer de 10 $\mathrm{ml}$. Las muestras fueron llevadas al laboratorio del hospital de la ciudad de Coracora para ser centrifugadas a $1600 \mathrm{~g}$ durante 5 minutos. El suero sanguíneo resultante fue mantenido a $-20^{\circ} \mathrm{C}$ hasta su análisis. 
Se determinó la seroprevalencia de animales positivos a anticuerpos contra Diarrea Viral Bovina, con su respectivo intervalo de confianza al 95\% (Wayne, 2012). Así también, se determinó la prevalencia corregida tomando en cuenta los índices de sensibilidad (96\%) y especificidad (97\%) de la prueba de ELISA utilizando el kit comercial IDEXX BVDV Total $A b \AA$, con sus respectivos intervalos de confianza al 95\% (Thursfield, 1990; IDEXX, 2013). Se evaluó la asociación entre la presencia de anticuerpos contra DVB frente a sexo, categoría zootécnica, raza, procedencia y estado reproductivo mediante la prueba de Chi cuadrado (Martínez, 2009).

\section{Resultados}

El 79.78 $\pm 3.64 \%(367 / 460)$ de las muestras presentaron anticuerpos contra el VDVB evidenciando una prevalencia corregida de $82.56 \pm 3.44 \%$ (Cuadro 1). A nivel distrital, Pullo presentó la mayor frecuencia de animales positivos $(89.74 \% \pm 2.75 \%, 83 / 96)$. En relación a la categoría animal, las vacas presentaron la mayor frecuencia de anticuerpos contra el VDVB $(91.96 \pm 2.46 \%, 293 / 331)$, mientras que los terneros fueron los menos afectados $(46.40 \pm 4.52 \%, 6 / 13)$.

En cuanto a la raza, el ganado criollo obtuvo la mayor frecuencia de positivos $(85.16 \pm 3.22 \%, 217 / 264)$. No se encontraron diferencias significativas con relación al estado reproductivo y la presencia de anticuerpos contra el VDVB.

El diagrama de caja y bigotes muestra una mayor dispersión de edades en los bovinos positivos a Ac-DVB que en bovinos negativos (Figura 1). El rango de edades de animales negativos a la prueba varió entre 4 meses y 8 años, especialmente en edades entre 2 y 4 años. En el caso de los animales positivos al VDVB, la edad varió entre 5 meses y 12 años, siendo la mayoría de 3 a 7 años, con una mediana de 5 años. Para el número de partos, se aprecia valores atípicos para los animales positivos a la prueba diagnóstica. La mayoría de los animales negativos tenía entre 1 y 3 partos.

\section{Discusión}

La seroprevalencia de anticuerpos frente al VDVB en el presente estudio fue de $79.78 \pm 3.64 \%$ (367/460) con una prevalencia corregida de $82.56 \pm 3.44 \%$, similar a la reportada en un estudio previo en la provincia de Parinacochas de $85.3 \%$ (Rivera et al., 2001). Otros estudios en el país presentan un rango variado de prevalencias de la enfermedad; así, 96 y $64.7 \%$ en el Valle del Mantaro, Junín (Ståhl et al., 2002 y Arauco y Lozano, 2018, respectivamente), 565 en Lima (Aguilar et al., 2006), 98.04\% en la Irrigación de Majes, Arequipa (Huamán et al., 2007), 48.7\% en Melgar, Puno (Quispe et al., 2008) 56.2\% en Espinar, Cusco (Cárdenas et al., 2011); 27.1\% en San Pablo, Cajamarca (Herrera et al., 2011); 75.3\% en Ayacucho (Bautista, 2011) y $60.4 \%$ en Paucarcolla, Puno (Choquenaira, 2018). Estos estudios demuestran la alta difusión de la enfermedad en el país en las dos últimas décadas, posiblemente debido al rol que cumplen los animales PI en los hatos (Morales et al., 2002), así como por las deficientes prácticas de manejo y ausencia de medidas de prevención y control.

El sexo (hembra) y la categoría zootécnica (vaca) mostraron asociaciones significativas con los niveles de anticuerpos contra el VDVB, pudiendo deberse a una mayor predisposición a eventos de inmunodepresión por el parto y la gestación, lo que facilita la coinfección con otros agentes virales (Betancur et al., 2007; Corro et al., 2017). Por otra parte, se reporta que los animales mayores de dos años presentan mayor frecuencia de presencia de anticuerpos contra el virus, posiblemente debido a una mayor exposición al virus y oportunidad de infección (Aguilar et al., 2006; Quispe et al., 2008; Nava et al., 2013). 
Cuadro 1. Seroprevalencia de anticuerpos contra el virus de Diarrea Viral Bovina $(n=460)$ en bovinos de crianza extensiva de los distritos de Pullo, Chumpi y Coracora, Ayacucho (Perú, 2018)

\begin{tabular}{|c|c|c|c|c|}
\hline \multirow[b]{2}{*}{ Variable } & \multicolumn{2}{|c|}{ Bovinos } & \multirow[b]{2}{*}{$\begin{array}{l}\text { Seroprevalencia } \\
\quad(\% \pm \text { IC })\end{array}$} & \multirow{2}{*}{$\begin{array}{c}\text { Prevalencia } \\
\text { corregida } \\
(\% \pm \mathrm{IC})\end{array}$} \\
\hline & $\begin{array}{c}\text { Total } \\
\text { (n) }\end{array}$ & $\begin{array}{l}\text { Positivos } \\
\text { (n) }\end{array}$ & & \\
\hline \multicolumn{5}{|l|}{$\mathrm{Sexo}^{1}$} \\
\hline Macho & 63 & 36 & $57.14 \pm 4.48$ & $58.22 \pm 4.47$ \\
\hline Hembra & 397 & 331 & $83.38 \pm 3.37$ & $86.43 \pm 3.10$ \\
\hline \multicolumn{5}{|c|}{ Categoría zootécnica $^{1}$} \\
\hline Ternero & 13 & 6 & $46.15 \pm 4.52$ & $46.40 \pm 4.52$ \\
\hline Vaquilla & 46 & 24 & $52.17 \pm 4.53$ & $52.87 \pm 4.52$ \\
\hline Torete & 43 & 24 & $55.81 \pm 4.50$ & $56.78 \pm 4.49$ \\
\hline Vaca & 331 & 293 & $88.52 \pm 2.89$ & $91.96 \pm 2.46$ \\
\hline Toro & 13 & 9 & $69.23 \pm 4.18$ & $71.22 \pm 4.10$ \\
\hline Vaquillona & 14 & 11 & $78.57 \pm 3.72$ & $81.26+3.54$ \\
\hline \multicolumn{5}{|l|}{$\mathrm{Raza}^{1}$} \\
\hline Criollo & 264 & 217 & $82.20 \pm 3.47$ & $85.16 \pm 3.22$ \\
\hline Holstein & 11 & 10 & $90.91 \pm 2.60$ & $94.53 \pm 2.06$ \\
\hline Brown Swiss & 139 & 104 & $74.82 \pm 3.93$ & $77.23 \pm 3.79$ \\
\hline Simmental & 33 & 31 & $93.94 \pm 2.16$ & $97.78 \pm 1.33$ \\
\hline Hereford & 13 & 5 & $38.46 \pm 4.41$ & $38.13+4.40$ \\
\hline \multicolumn{5}{|l|}{ Procedencia $^{1}$} \\
\hline Chumpi & 118 & 99 & $83.90 \pm 3.33$ & $86.99 \pm 3.05$ \\
\hline Coracora & 246 & 185 & $75.20 \pm 3.91$ & $77.63 \pm 3.78$ \\
\hline Pullo & 96 & 83 & $86.46 \pm 3.10$ & $89.74 \pm 2.75$ \\
\hline \multicolumn{5}{|l|}{ Estado reproductivo $^{2}$} \\
\hline Vacía & 312 & 276 & $88.46 \pm 2.89$ & $91.89 \pm 2.47$ \\
\hline Preñada & 19 & 17 & $89.47 \pm 2.78$ & $92.98+2.31$ \\
\hline Sub-total & 331 & 293 & $88.52 \pm 2.89$ & $91.96 \pm 2.46$ \\
\hline Total & 460 & 367 & $79.78 \pm 3.64$ & $82.56 \pm 3.44$ \\
\hline
\end{tabular}

${ }^{1}$ La variable sexo, categoría zootécnica, raza y procedencia presentan asociación significativa $(p<0.05)$ frente a anticuerpos al VDVB

${ }^{2}$ La variable estado reproductivo no presentó asociación significativa frente a anticuerpos al VDVB 

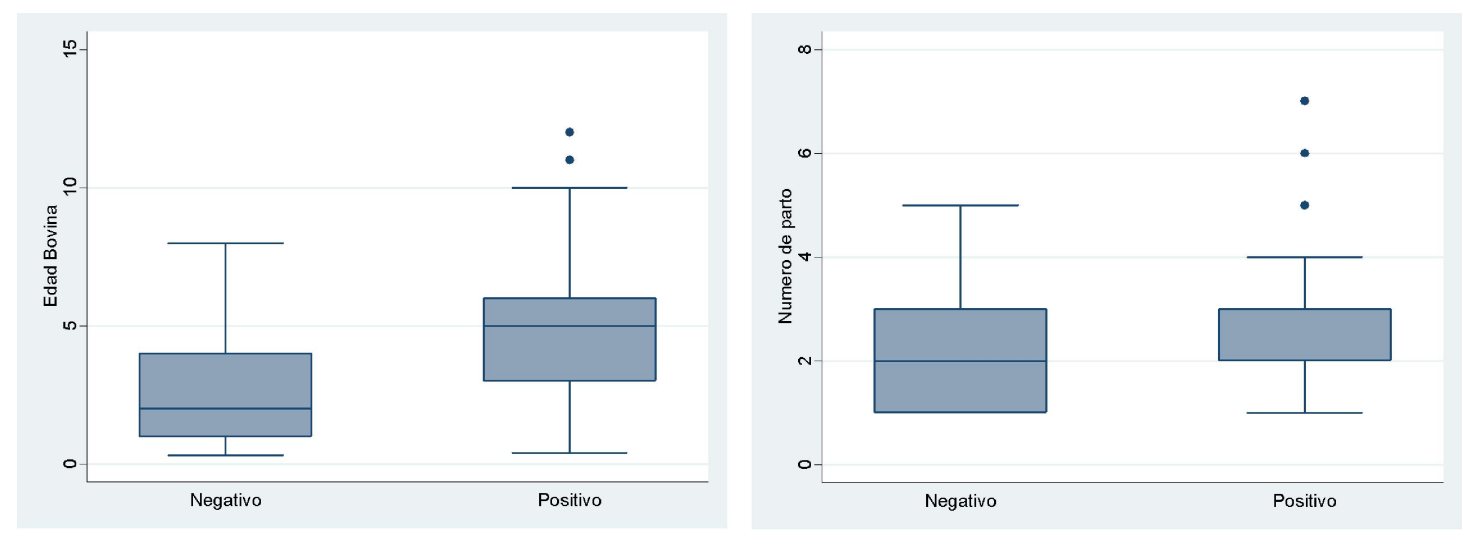

Figura 1. Diagrama de caja y bigotes de bovinos de tres distritos de la provincia de Parinacochas, Ayacucho, según resultado a la prueba diagnóstica de anticuerpos contra el VDVB. Izquierda: Según la edad; Derecha: Según el número de partos

Los bovinos Simmental presentaron una prevalencia corregida de $97.78 \pm 1.33 \% \mathrm{y}$ los Holstein de $94.53 \pm 2.06 \%$, siendo estas razas las más afectadas. Sin embargo, esto no guarda relación con estudios previos en los que se establece que los bovinos criollos son más susceptibles a la enfermedad, debido a condiciones de estrés, deficiencias nutricionales e infecciones secundarias (Rivera et al., 2001; Quispe et al., 2008).

La mayor prevalencia corregida frente al VDVB de $89.74 \pm 2.75 \%$ en el distrito de Pullo ( $\mathrm{p}<0.05)$, puede deberse a las condiciones de crianza en ese distrito, donde las áreas de pastoreo no presentan delimitaciones entre hatos, además de la falta de conocimiento por parte de los ganaderos acerca de la enfermedad, lo que conlleva a introducir bovinos sin diagnóstico previo (Huamán et al., 2007; Gonzales, 2016).

El presente estudio muestra la difusión del VDVB en el departamento de Ayacucho, la cual se mantiene según evidencias de estudios anteriores (Rivera et al., 2001; Bautista, 2011). La infección por el VDVB ocasiona grandes pérdidas económicas a los ganaderos, por lo que debería, realizarse medi- das de control, prevención y erradicación (Evans et al., 2018; Marschik et al., 2018). Por ello, debe promoverse capacitaciones a los técnicos y ganaderos de la región acerca de la enfermedad, implementar medidas de bioseguridad que comprendan un control del ingreso de nuevos bovinos al hato mediante la realización de cuarentenas, detección de bovinos PI y uso de semen certificado libre de enfermedad, así como establecer calendarios de vacunación y la implementación de pruebas diagnósticas como estrategia de erradicación (Vargas et al., 2009; Rypula et al., 2013; Evans et al., 2018; Moenning y Becher, 2018).

\section{Conclusiones}

- La prevalencia corregida de anticuerpos contra el VDVB fue de $82.56 \pm 3.44 \%$ en los distritos de Coracora, Pullo, y Chumpi, provincia de Parinacochas, Ayacucho.

- Existe asociación estadística significativa $(p<0.05)$ entre sexo, categorías zootécnicas, raza y procedencia con la positividad a anticuerpos contra el virus de la DVB en los distritos de estudio. 


\section{Literatura Citada}

1. Aguilar R, Benito A, Rivera H. 2006. Seroprevalencia del virus de la diarrea viral bovina en ganado lechero de crianza intensiva del valle de Lima. Rev Inv Vet Perú 17: 148-153. doi: 10.15381/ rivep.v17i2.1530

2. Araínga $M$, Rivera H, Huamám J, Manchego A. 2010. Fenotipo y genotipo del virus de la diarrea viral aislado de bovinos en el Perú. Rev Inv Vet Perú 21: $192-$ 203. doi: 10.15381 /rivep.v21i2.-137

3. Arauco F, Lozano E. 2018. Seroprevalencia de diarrea viral bovina en hatos lecheros del Valle del Mantaro, Región Junín, Perú. Rev Inv Vet Perú 29: 15151526. doi: 10.15381/rivep.v29i4.15347

4. Aronés M, Apel K, Caro I, Castillo L, Hurtado L, Quinteros E, Vargas $C$. 2003. Centralismo y descentralización en Ayacucho. [Internet]. Disponible en: https://www.academia.edu/3367764/ UN BREVE PERFIL DE PARINACOCHAS

5. Bautista F. 2011. Seroprevalencia del virus de la diarrea viral bovina en las cuencas ganaderas de cinco distritos de la región Ayacucho. Tesis de Médico Veterinario. Ayacucho, Perú: Univ. Nacional de San Cristóbal de Huamanga. 57 p.

6. Betancur H, Gogorza L, Martinez $F$. 2007. Seroepidemiología de la diarrea viral bovina en Monteria. Analecta Vet 27: 11- 16.

7. Bolin SR, Grooms DL. 2004. Origination and consequences of bovine viral diarrhea virus diversity. Vet Clin N AmFood A 20: 51-68. doi: 10.1016/ j.cvfa.2003.11.009

8. Brodersen B. 2014. Bovine viral diarrhea virus infections: Manifestations of infection and recent advances in understanding pathogenesis and control. Vet Pathol 51: 453-464. doi: 10.1177/ 0300985813520250

9. Cárdenas A, Rivera H, Araínga M, Ramírez M, De Paz J. 2011. Prevalencia del virus de la diarrea viral bovina y de bovinos portadores del virus en bovi- nos en la provincia de Espinar, Cusco. Rev Inv Vet Perú 22: 261-267. doi: 10.15381/rivep.v22i3.268

10. Choquenaira A. 2018. Seroprevalencia del virus de la diarrea viral bovina (vDVB) en la raza Brown Swiss del distrito de Paucarcolla. Tesis de Médico Veterinario y Zootecnista. Puno: Univ. Nacional del Altiplano. $79 \mathrm{p}$.

11. Corro A, Escalona J, Mosquera O, Vargas F. 2017. Factores de riesgo asociados a la seroprevalencia de Diarrea Viral Bovina en vacas y novillas no vacunadas en el Municipio Bolívar del estado Yaracuy, Venezuela. Gaceta Cienc Vet 22: 27-32.

12. Evans CA, Pinior B, Larska M, Graham D, Schweizer M, Guidarini C, Decaro N, et al. 2019. Global knowledge gaps in the prevention and control of bovine viral diarrhoea (BVD) virus. Transbound Emerg Dis 66: 640652. doi: 10.1111/tbed.13068

13. Fulton RW, Ridpath JF, Saliki JT, Briggs RE, Confer AW, Burge LJ, Purdy $\mathrm{CW}$, et al. 2002. Bovine viral diarrhea virus (BVDV) 1b: predominant BVDV subtype in calves with respiratory disease. Can J Vet Res 66: 181-190.

14. Fulton RW, Ridpath JF, Confer AW, Saliki JT, Burge LJ, Payton ME. 2003. Bovine viral diarrhoea virus antigenic diversity: impact on disease and vaccination programmes. Biologicals 31 : 89-95. doi: 10.1016/S1045-1056(03)00021-6

15. Gonzales K. 2016. Estudio de la prevalencia de diarrea viral bovina en ganaderías del Cantón Saraguro, provincia de Loja. Tesis de de Médico Veterinario Zootecnista. Loja: Univ. Nacional de Loja. $75 \mathrm{p}$.

16. Herrera A, Manchego A, Ramírez M, More J, Rivera H. 2011. Seroprevalencia del virus de la diarrea viral en bovinos de crianza extensiva de la provincia de San Pablo, Cajamarca. Rev Inv Vet Perú 22: 171-175. doi: 10.15381/ rivep.v22i2.294 
17. Huamán JC, Rivera H, Araínga M, Gavidia C, Manchego A. 2007. Diarrea viral bovina y bovinos portadores del virus en hatos productores de leche de la irrigación de Majes, Arequipa. Rev Inv Vet Perú 18: 141-149.

18. IDEXX Laboratories. 2013. IDEXX BVDV Ab Test. Test With Confidence. p 22-26.

19. INEI. Instituto Nacional de Estadística e Informática. 2012. IV Censo Nacional Agropecuario: Existencia de ganado, aves, otros bovinos y colmenas. Lima. [Internet]. Disponible en: http:// censos.inei.gob.pe/Cenagro/redatam/

20. Lanyon SR, Hill FI, Reichel MP, Brownlie J. 2014. Bovine viral diarrhoea: pathogenesis and diagnosis. Vet J 199: 201-209. doi: 10.1016/j.tvj1.2013.07.024

21. Lértora WJ. 2003. Diarrea viral bovina: actualización. Rev Vet 14: 42-51.

22. Marschik T, Obritzhauser W, Wagner P, Richter V, Mayerhofer M, EggerDanner C, Käsbohrer A, Pinior B. 2018. A cost-benefit analysis and the potential trade effects of the bovine viral diarrhoea eradication programme in Styria, Austria. Vet J 231: 19-29. doi: 10.1016/j.tvj1.2017.11.010

23. Martínez M. Bioestadística amigable. 2009. $2^{\circ}$ ed. España: Ed Díaz de Santos. $936 \mathrm{p}$.

24. Moenning V, Becher P. 2018. Control of bovine viral diarrhea. Pathogens 7:29. doi: 10.3390/pathogens 7010029

25. Morales S, Benito A, Rivera H. 2002. Terneros persistentemente infectados con el virus de la diarrea viral bovina en dos hatos lecheros de la provincia de Arequipa. Rev Acad Per Cienc Vet 3: 8-13.

26. Nava Z, Bracamonte M, Hidalgo M, Escobar R. 2013. Seroprevalencia de la diarrea viral bovina en rebaños lecheros de dos municipios del estado Barinas, Venezuela. Rev Soc Ven Microbiol 33: 162-168.
27. Neill JD, Crossley BM, Mosena AC, Ridpath JF, Bayles DO, Hietala SK, Killian ML, et al. 2019. Genomic and antigenic characterization of cytopathic bovine viral diarrhea virus $1 \mathrm{i}$ isolated in the United States. Virology 535: 279-282. doi: 10.1016/j.virol.2019.07.020

28. Nettleton PF, Entrican G. 1995. Ruminant pestiviruses. Brit Vet J 151: 615-642. doi: 10.1016/S0007-1935(95)80145-6

29. [OIE] Organización Mundial de Salud Animal. 2021. Enfermedades, infecciones e infestaciones de la Lista de la OIE en vigor en 2021. [Internet]. Disponible en: https://www.oie.int/es/sanidad-animal-en-el-mundo/enfermedadesde-la-lista-de-la-oie-2021/

30. Quispe R, Ccama A, Rivera H, Araínga M. 2008. El virus de la diarrea viral en bovinos criollos de la provincia del Melgar, Puno. Rev Inv Vet Perú 19: 176-182. doi: 10.15381/ rivep.v19i2.1165

31. Ricci S, Bartolini S, Morandi F, Cuteri V, Prezluso S. 2019. Genotyping of Pestivirus A (Bovine viral diarrhea virus 1) detected in faeces and in other specimens of domestic and wild ruminants at the wildlife-livestock interface. Vet Microbiol 235: 180-187. doi: 10.1016/j.vetmic.2019.07.002

32. Rivera H, Valdivia L, Benito A. 2001. Diarrea viral bovina en bovinos lecheros de crianza semi-intensiva de la provincia de Parinacochas, Ayacucho. Rev Inv Vet Perú 1: 380-381.

33. Rosemberg M. 2018. La ganadería bovina en Perú. [Internet]. Disponible en: http://www.veterinariadigital.com/ articulos/la-ganaderia-bovina-en-peru

34. Rypula K, Ploneczka-Janeczko K, Bania J, Walecka E, Bierowiec K, Rozpedek W. 2013. Reduction of prevalence of persistent BVDV infection in cattle herds by long-term vaccination program (preliminary clinical study). Pol 
J Vet Sci 16: 381-383. doi: 10.2478/pjvs2013-0051

35. Sandvik T. 2005. Selection and use of laboratory diagnostic assays in BVD control programmes. Prev Vet Med 72: 3-16. doi: 10.1016/j.prevetmed.2005.08.015

36. [SENASA] Servicio Nacional de Sanidad Agraria. 2015. Enfermedades notificables. [Internet]. Disponible en: https:// www.senasa.gob.pe/senasa/6398-2/

37. Ståhl K, Rivera H, Vagsholm I, Moreno-Lopéz J. 2002. Bulk milk testing for antibody seroprevalences to BVDV and BHV-1 in a rural región of Peru. Prev Vet Med 56: 193-202. doi: 10.1016/ s0167-5877(02)00161-7

38. Thursfield M. 1990. Epidemiología veterinaria. España: Ed Acribia. 42 p.
39. Vargas DS, Jaime J, Vera VJ. 2009. Perspectivas para el control del Virus de la Diarrea Viral Bovina (BVDV). Rev Colomb Cienc Pec 22: 677-688.

40. Vilcek S, Durkovic B, Kolesarova M, Paton DJ. 2005. Genetic diversity of BVDV: Consequences for classification and molecular epidemiology. Prev Vet Med 72: 31-35. doi: 10.1016/j.prevetmed.2005.08.004

41. Wayne D. 2012. Bioestadística base para el análisis de las ciencias de la salud. $4^{\mathrm{a}}$ ed. México DF: LIMUSA. 517 p.

42. Yesilbalg K, Alpay G, Becher P. 2017. Variability and global distribution of subgenotypes of bovine viral diarrhea virus. Viruses 9: 128. doi: 10.3390/ v9060128 